\title{
Reframing and Redefining Family Therapy: Ubuntu Perspective
}

\author{
S.H. Somni* \\ N.S. Sandlana* \\ Department of Psychology, University of Fort Hare, Private Bag x 1314, Alice, 5700 South Africa \\ Email: somnisimani@gmail.com/Email: nsandlana@ufh.ac.za
}

\section{Doi:10.5901/mjss.2014.v5n23p2158}

\section{Abstract}

Most Western theorists and practices have undermined the richness of African indigenous cultural practices that have been in existence from time immemorial. Furthermore, ignorance concerning African values has led to the development of a negative attitude towards African culture. This necessitates a need for ways of knowing that are legitimate and valuable as those of the West, ways that will embrace African values. An African value that sets the pace for most Africans is Ubuntu. Ubuntu is rooted in the African worldview which embraces interconnectedness, interdependence and spirituality. Unlike in conventional methods of healing, this value transcends the self to include significant others in one's social world and therefore promotes collectivism and communalism among family members. Like other conventional forms of treatment, traditional family therapy is based on western principles and as such fails to meet the needs of the Black African population. It is against this background that the researchers seeks to redefine and restructure family therapy using Ubuntu perspective as an endeavour to enhance provision of a culture specific and sensitive family therapy. The paper is based on the explorative qualitative study that was conducted in the Nkonkobe municipality of the Eastern Cape, using focus group discussions. The research findings revealed that lack of Ubuntu is the main cause of family problems and as such the researchers recommend redefinition and restructuring of strategies used by conventional therapist in helping families deal with their problems.

Keywords: Family, family therapy, reframing, redefining, Ubuntu.

\section{Introduction}

On a daily basis the rate at which South Africans are divorcing is on the rise, the rate of job losses is escalating and there is an outbreak of rape of women and children. There is also the HIVIAIDS pandemic which sometimes leads to childheaded families. There exist violent ethnic and political clashes which occur on a daily basis. Survivors of such atrocities do not only experience painful memories which haunt them, but also lose hope in life. These affect their family functioning negatively or configure a variety of family types. Tlou (2014) suggests that South Africa has a number of family types, including the single-mother family which is a result of failed relationship or divorce, the skipped- generation parented family where grandparents are playing the parental role, the child- headed family as a result of HIVIAIDS, bigamous or polygamous family created by migration, same-sex parent family and the cross-racial adoption family. According to Holborn and Eddy (2011) these atrocities may give rise to broken families. The incidents necessitate that therapeutic measures be taken to restore sanity and tranquillity among families using an approach or a combination of approaches (Kasiram \& Oliphant, 2007). One of the available approaches for family therapy is the Ubuntu perspective. Ubuntu implies that no one person can be self-sufficient and therefore emphasises interdependence, hence the saying in isiXhosa,"umntu ngumntu ngabantu" which literally means, "a person is a person because of others" (Broodryk, 2006, p.17). The saying goes hand in hand with such statements as "your pain is my pain, my wealth is your wealth, and your salvation is my salvation" (Nussbaum, 2003, p.2).

Previous studies on family therapy reveal that family problems can either be child-focused, adult focused or can cut across all ages (Lee, Greene, Hsu, Solovey, Grove, Fraser, Washburn \& Teater, 2009). Engelbrecht and Kasiram (2012) argue that in multicultural countries like South Africa, applying Western or European models of therapy to African clients has a tendency of resulting in conflict. African clients are raised in an environment that practices collectivism whereas Western models of therapy are more individualistic in nature. Kasiram and Oliphant (2007) reveal that family therapy in South Africa challenges the Western approach. Western approach focuses on the nuclear family whereas African models focus on the extended family. According to Tlou (2014) there are unique kinship patterns that are found in African families. These patterns include extended family and kinship networks (the ties that bind the families), the nuclear family 
as part of an extended family (separate but still a part), fostering or informal adoption, mothering (role played by biological mother, aunts, grandmother), fathering (biological father, grandfather and uncles).

Kasiram and Oliphant (2007) argue that a therapist in South Africa should see the world through the African context, appreciating the rituals and African religion in order to create new, context-relevant therapies. This means that South Africa, and perhaps Africa, requires a deviation from the traditional western family therapy practice. This is where the Ubuntu perspective comes in. In this research, the Ubuntu perspective will be explored as a complementary approach to western family therapy.

A few researchers have explored the way Ubuntu could be utilised to promote a culturally appropriate approach to mental health care. In a study conducted by Engelbrecht and Kasiram (2012), when they were exploring the role of Ubuntu in families living with mental illness, they discovered that these families experience stigma and isolation in the community and this indicates a lack of Ubuntu which, according to the African culture, is regarded as a life philosophy (Engelbrecht \& Kasiram, 2012). Engelbrecht and Kasiram (2012) explain that there appeared to be elements of hate, distrust, and even exploitation of defenceless families. All these elements are far removed from the Ubuntu way of living. The authors further explain that these families experience high levels of burden of care. People with mental illness are more likely to be unemployed and that puts a lot of financial strain to the family. The burden of care deepens when the illness worsens because there will be a need for supervision and assistance from other family members.

Makhele (2009), in the research on the experiences of Batswana families regarding Hospice care of Aids patients discovered that hospitals discharge AIDS patients early in order to be cared for by their families and some by hospices. Makhele (2009) explains that the family structure is viewed as a place of care, and that this view is supported by the philosophy of Ubuntu which the Batswana people strongly subscribe to. Using a qualitative, exploratory and contextual design, Makhele (2009) discovered that the families of Aids patients experienced stigmatisation and alienation. Makhele's study revealed a lack of Ubuntu and explained why some families preferred to send their HIVIAIDS terminally ill members to hospices even though hospices are regarded by some people as a western approach to AIDS care. Some people also argued that a hospice is foreign to their cultural practices because it encourages the ill loved ones to be cared for by strangers (Makhele, 2009). Ubuntu plays a vital role in peace-making through the principles of forgiveness, understanding, inclusivity, and a sense of shared destiny between not only to communities but also between a husband, a wife and the in-laws.

In a study conducted by Masina (2009) on conflict resolution in marriage, the author argues that marriage in African communities is not just one spouse marrying the other, but a collective union of two extended families. The role of these extended families is to ensure that there is encouragement, trust, caring, respect, sympathy and empathy in a marriage. Whenever there are marital problems between a husband and a wife, the principle of inclusivity comes into operation. As discussed by Masina (2009) the elders or the go- betweens or the chief and his aides are called as mediators to resolve the problems. If the problems are not resolved, the wife goes back to her family to seek protection. If the conflict reaches such a level, the husband is expected to send members of his family to negotiate her return in order to protect the dignity of the entire family. This clearly portrays interdependence, where people rely on each other for support and for survival.

\section{Research Method}

An exploratory qualitative study was conducted. The aim of this method was that the researcher intended to listen to families about how they deal with family problems and whether they make use of Ubuntu principles, if so, what are those. Exploratory qualitative research is designed to make preliminary investigations into fairly unknown areas of research in an attempt to look for new insights (Terre Blanche, Durrheim \& Painter, 2006). The reason for choosing exploratory design was that there is lack of documented information regarding the use of Ubuntu in family therapy. Qualitative method is a practical technique aimed at describing and interpreting the experiences of research participants (Ponterotto, 2005). In this paper the experiences of participants will be described and interpreted.

\subsection{Population and Sample}

For the purpose of this study, the population used was families living in the Nkonkobe Municipality, which forms part of the Amathole District Municipality, of the Eastern Cape Province, which is predominantly rural. The study was conducted in the Golf Course Township within the municipality. This community has been chosen because of its close proximity to the University of Fort Hare.

The researcher selected sample members purposefully. Purposive sampling is sometimes referred to as 
judgmental or selective sampling as it involves the researcher consciously selecting the participants who are rich with information (Burns \& Grove, 2005). The sample consisted of thirty (30) participants, comprised of fifteen (15) families with two (2) family members each. The study included only Golf Course families, and excluded individuals who are not living with their families and those who are younger 30 years old. The reasons for exclusion were that the focus of the study was on mature family members who were professed to be knowledgeable about Ubuntu.

\subsection{Research Instrument}

The researcher chose a focus group discussion to gain more information about the topic. Terre Blanche, Durrheim and Painter (2006) recommend that focus group size should range from 6-12 people. For the purpose of this study, three (3) focus group discussions were conducted by the researcher. The first group had (12) twelve participants, the second group had (07) seven and the third group had (11) eleven participants. Each focus group discussion took an hour. The focus group discussion has its advantages and disadvantages.

Focus group discussions are useful when time is limited and multiple viewpoints are required on a specific topic (De Vos, 2012). It enables participants to feel more comfortable talking in a group rather than alone. Interaction among the focus group members may be more informative than individually conducted interviews (Leedy \& Ormrod, 2005). Thick text was obtained during interview sessions through which the illustrative quotes or voices of the participants were recorded. According to De Vos (2012) focus group method of data collection on the other hand can be very costly and requires a researcher that is skilful in group dynamics. Focus group discussions are susceptible to facilitator bias which can undermine the validity and the reliability of the research. Discussion can be side-tracked or dominated by few individuals.

A semi-structured focus group guide with a series of core questions was developed to steer the discussion. These core questions were taken from the research questions about the role of Ubuntu in solving their family problem. The issues discussed included perceptions of families regarding Ubuntu, common problems faced by families, traditional ways of solving family problems, role played by elders in solving family problems, use of Ubuntu principles and traditions to solve family problems and collaboration between western and Ubuntu therapy.

\subsection{Trustworthiness}

Trustworthiness ensures reflection of the true state of the phenomena in qualitative research. It is the criteria of evaluating the data obtained as well as the complex research procedures followed in qualitative studies. The following criteria for establishing the trustworthiness of the study were ensured (i) conformability (ii) transferability which was through a thick description of the study and its processes during the enquiry. Sufficient information is available to enable transferability therefore the results can be applicable to different settings and (iii) credibility; the study is based on lived experiences of Golf Course community members.

\section{Results and Discussion}

The major themes emerged from the focus group discussions with participants when they expressed their experiences regarding the use of Ubuntu principles in healing families are the following:

\subsection{Knowledge and perception about Ubuntu}

The research findings revealed that participants have in-depth knowledge and understanding of Ubuntu. The researcher found that participants had more knowledge about Ubuntu and they kept on referring to what was happening in the ancient times when they were growing up as children. Many research participants indicated that these special qualities are learnt during primary socialization as children.

One participant commented,

"Ubuntu sisiphiwo umntu azelwe naso okanye asifundiswa ngabantu abadala kwasebuntwaneni ehamba nokukhathalela abanye nokuthembakala, ukuthobeka, ukunyamezelana".

[Ubuntu is a special quality that a person is born with or that is taught during childhood by elders that comprises care for others, trustworthiness, humility and tolerance] (Smiling). 
Another participant said,

"Ukuhlalisana kakuhle nangoxolo, ngothandana, uvelwano, ukwabelana, ukuncedana, intlonipho"

[Living together in harmony, love, compassion, sharing, respect and helping each other] (Smiling with a little bit of laughter).

The participants gave a detailed definition on Ubuntu as special qualities that a human being is born with or taught during childhood by the elders that include living together in harmony with love for one another, sharing of resources, respect for human dignity and helping one another, trustworthiness, humility and tolerance. This definition is in line with that of Nussbaum (2003) that says in African culture Ubuntu is the capacity to express compassion, reciprocity, dignity, harmony and humanity in the interest of building and maintaining community justice and mutual caring (Nussbaum, 2003). According to Ubuntu principles there is no man who is an island or self-sufficient, therefore building a network of interdependent relationships that are based on unconditional acceptance, mutual care and support is crucial. Some research participants have also acknowledged that most people have lost the meaning of Ubuntu hence there is so much dissonance among community members.

According to Broodryk (2010) Ubuntu principle of humaneness places all human beings on the fore and also embraces a Xhosa saying that says "Umntu ngumntu ngabantu" (which means I am because of others). Broodryk (2010) further asserts that humaneness is one of the primary principles of Ubuntu that is comprised with secondary values that include humanity, tolerance, understanding, peace, helpfulness and warmth.

Ubuntu is a virtue that is highly esteemed and venerated and it is absolutely necessary for each and every individual to possess it. Living the Ubuntu way, brings about respect for human dignity and obedience; compassion that consist of love and forgiveness; sharing that is based on unconditional giving and redistribution; caring that promotes empathy and sympathy; and humanness that is driven by humanity and warmth. Contrary to the above statement, Ubuntu is also lacking in our society and that has brought so many ills in our communities. Now people are so afraid to walk freely in their streets without watching their backs, it is not safe even in their homes, fearing to be attacked for no reason. Ubuntu advance communality and the spirit of togetherness especially amongst African communities as they enjoy sharing.

\subsection{Common family problems}

The research findings indicated that families are surrounded with serious problems. The majority of the participants indicated that at Golf Course they face many challenges, which impact negatively in society. In addition, these challenges erode the moral fabric of society, amongst others, that is, respect for the elderly. These challenges include excessive drinking and drug abuse among spouses and their children, illnesses (HIVIAIDS, mental illness, and others), teenage pregnancy, domestic violence, elderly being abused by their children, cheating spouses and spousal abuse, assault and rape, poverty and unemployment. For example, one participant exclaimed,

"Intombi yam inxila kakhulu. Xa enxilile ke yhoo uthetha kakubi nam, uyandithuka andinukuneze. Ngamanye amaxesha uyandinyola andigxagxamise. Ngamanye uye ayithathe yonke imali yam yendodla"

[My daughter drinks too much and when she is drunk she becomes abusive verbally and sometimes physically towards me. At times she would take all my pension grant money and spend it on liquor] (crying).

Another participant said angrily,

“Umyeni wam wayeqhele ukundibetha qho kanti uthandana nomntan' eskolo. Ngoku uyagula ufuna ndimonge, Naloo nkazana yakhe yomntan' esikolo iyagula"

[My husband used to beat me up and I discovered that he had an affair with a school girl. Now he wants me to take care of him because his is so sick and even his school girl mistress is sick too] (fuming).

During discussion most of the research participants shared some moving personal chronicles. One participant burst into tears when narrating his loss,

"Ndalahlekelwa ngamalungu efamily amaninzi ngenxa kagawulayo, bandishiya nomsebenzi omkhulu wokukhulisa nokukhathalela abantwana babo. Akululanga tuu kwaphela kuba nam ndinolwam usapho olusandidingayo. Yonke ke lento yehla ndingaphangeli" "II have lost most of my family members due to HIVIAIDS and now I am left with a huge responsibility of taking care of their children. It is not easy at all because my family also need me yet l'm not working] (Crying). 
According to Holborn and Eddy (2011) HIVIAIDS has left so many families fractured in various ways. Some families have lost their sole bread winner, some both parents and these situations have forced the eldest child to become the head of the household. These problems clearly undermine the social functioning of the families as they are deeply affected psychologically, emotionally, mentally and physically. According to Ubuntu principle of caring when children lose their parents, their extended families take care of them (Broodryk, 2010). The lack of respect from children for their elders undermines the principles of Ubuntu.

According to Ubuntu principles, respect is an important moral concept that stipulates authority elders have over young people and parents over children and men over women (Broodryk, 2006). A study conducted by Eddy and Holborn (2011) revealed that $73 \%$ of young people admitted to using alcohol and drugs. The use of drugs and alcohol has a strong connection to youth offences and rate of ill-treatment. According to Statistics South Africa many families, especially children, are affected by divorce. The distribution of number of families affected by divorce in 2010 shows that $37,9 \%$ from black African population group; $27,6 \%$ from white population group; $17,3 \%$ from coloured population group and 5,5\% from Indian/Asian population group. The divorce rate among black African population is taking a lead.

Most families are faced with various problems hence there is a need to revive the use of Ubuntu principles in solving these problem as it was done in the past. So many interventions have been made with little or no significant improvement. Government has introduced so many laws as a way of curbing some of these problems. The lack of Ubuntu has left our communities wounded because of the escalating crimes and vigilante justice, egoism among people, few people who are willing to help without gain or bribed; some are reluctant to help fearing for their lives.

\subsection{The role of culture and traditions in solving family problems}

Most research participants agreed that culture still has a significant role to play in solving family problems although it has been used minimally these days. Some research participants reported to utilize culture as the last resort after they have tried modern ways. For example, in cases of unexplained illness like barrenness and mental illnesses and enuresis (at adolescent stage and above), the family would first consult the western doctors then if there is no improvement or relief they will consult the traditional healer.

One participant responded by saying,

"Xa umfazi engade amithe, abantu bakulomyeni bayebacele abakhozi ukuba bayithathe intombi yabo ikhe iyokulungiswa. Abazali bentombi baye bacele izinyanya zabo ukuba zincede intombi yabo kulengxaki.Bathi ukuba banetyala lomsebenzi abangekawenzi bangxengxeze ngomlomo bavume ityala bathembise ukuba bakuthi xa imeko zivuma bawenze lomsebenzi okanye kuxhelwe ibhokhwe kungxengxeza kwizinyanya".

[When the wife is not able to conceive, the family of the husband would take request the family of wife to take her back in order to solve the problem. The wife's family would then request their ancestors help their daughter. If they know that there is still an outstanding ritual they owe to their ancestors, they acknowledge that indeed they are at fault and promise to perform the ritual when the conditions are favourable or slaughter a goat to appease their ancestors] (Composed).

One older participant declared,

"Amafufunyana wona anganyangwa ngendlela zesintu qha,amayeza esilungu awanawuze akwazi ukukhupha umoya omdaka."

[Amafufunyana can only be removed by traditional methods; Western medicine cannot remove evil spirits] (Laughing).

According to the above assertions indicate that when the traditional ritual has not be done in a family, that creates a conflict or mishap within the family. Juma (2011) argues that in an African worldview illnesses are the product of dissonance between people and the ancestors. The individual may suffer as a result of dissonance between the family and the ancestors and in order for peace to be restored; certain rituals need to be performed. According to Walaza (2005) there are various kinds of rituals that are performed for ancestors to guarantee continuous healthy relationship with the living descendants.

These rituals range from goat or cow slaughtering, cleansing and the use of herbal extracts. Goat or cow slaughtering is meant to appease the ancestors if there is a proof that the ancestors have been angered in anyway, to ask the ancestors to stop continued predicament the family is faced with, and for introducing the new member or a baby in the family to the ancestors for protection purposes. It is evident that the belief system of the family will determine the manner in which they will solve their problems. Most black Africans strongly believe that some family problems and 
misfortunes can only be solved by the intervention of the ancestors.

\subsection{Role of the elders in solving family problems}

All research participants admitted that elders play a significant role in family matters. The research participants also reported that in cases of illnesses within the family, the elders have to seek the counsel of the ancestors and appease the ancestors by performing a required ritual. Elders have a responsibility to facilitate family meetings and solve some disputes among family members with regard to the question of the role of elders in solving family problems. Some research participants also reported that elders lead a delegation whenever there is a need for the services of a traditional healer.

One participant stated,

"ukubiza intlanganiso zekhaya ukusombulula ingxabano nengxaki, ukuxoxa ngolwalusa nangokucela okanye ukulobola" [Calling family meetings to solve a dispute and problems, to discuss boys initiation/circumcision and for lobola negotiations] (Smiling).

Another participant explained,

"Ukungxengxeza nokucenga izinyanya, nokuvuma amatyala emisebenzi engekenziwa. Ukuphatha umsebenzi ngendlela esosiduko senzangayo"

[Calming down, acknowledging an outstanding ritual and apologising to theancestors. Performing rituals according to the clan name procedures] (composed).

Two other participants further explained,

"ukukhokela igqiza losapho eliya egqirheni ukuyova umhlola, uyokuva impendulo nokufuna ukuphila"

[Leading a delegation to see the traditional healer for guidance, for some answers and healing] (Frowning).

According to the above statements elders are very important in families and in society. Elders have a responsibility of transferring indigenous knowledge and traditions to the younger generation. Nwoye (2004) argues that the family setting in Africa was highly structured with parents and grandparent, occupying a decision-making position in such a set up. Siblings were considered as people in a learner position in the journey to responsible adulthood and were regarded as uninitiated and inexperienced. The services of grandparents were requested in child rearing and discipline. Nwoye (2004) argues that Africans employ the services of peer guidance or support of friends, senior siblings, relatives and elders to respond to their life's predicaments.

The role of elders is far more important than it looks in nowadays. No ritual can be performed without the presence and the leadership of the elders as they are the ones who have the authority to speak to the ancestors. They also hold the position of carrying the spear for slaughtering rituals. Elders are central in family functioning, as they are the custodians of the traditions and customs.

\subsection{Use of Ubuntu principles in solving family problems}

The findings indicated that Ubuntu principles have been used since the ancient times and were practised mainly by African people. The Ubuntu way of living was promoting communal living where community members would share their resources with less fortunate people and the needy. The research participants agreed on the notion that disciplined and respect among the younger generation can be instilled through the use of Ubuntu principles.

One annoyed participant had this to say with regard to instilling discipline,

"ukuba abazali banganenyani bona kuqala babaqeqeshe abantwana ngolahlobo babeqeqeshwe ngalo nabo. U"hayi" abe nguhayi u"ewe" abe ngu-ewe. Xa umntana emoshile umzali angamthetheleli. Singazamkeli izinto abaza nazo ezibiweyo or mazifumene ngendlela ezingaziwayo."

[If parents can be honest when disciplining their children as their parents were truthful in disciplining them. "No" must be no and "Yes" be yes. When a child has committed an offence, the parent should not bail out his or her child. We should not accept any stolen goods or goods that we don't know where they are coming from.] (Fuming).

One participant supported sadly by saying, 
"Ubuntu ibenza abantu bahlalisane ngoxolo ekhayeni, kungabikho kuhlukumezana. Umzekelo, ngelaxesha lethu indoda ehlukumeza umfazi ibidliwa inkomo ngabakhozi okanye onozakukuzaku. Abantwana bebengahlukunyezwa, badlwengulwe ngoyise nangomalume babo. Ukuba kungabuyelwa ekuhlonipheni isidima somntu nokuba ungakani ungakanani, sivuselele uthando. Singatsho sikhathalelane"

[Ubuntu creates a harmonious environment at home, free of abuse. For example, in our times a man that abuses his wife was fined a cow by the in-laws or the lobola negotiator. Children were not abused or raped by the fathers or uncles. If we can go back to respecting of human dignity irrespective of whom they are and age and revive love for one another. That can result in caring for one another] (Sad).

The participants did acknowledge that using Ubuntu principles to solve their problems is profitable because the custodian of Ubuntu is the very same community they reside in. The participants further affirm that they do not spend huge sums of money for these solutions as they are at their door step, meaning the use of elders. Mndende (2007) claims that parents have forsaken the Ubuntu ways of raising their children, that are culture centred. This has led to the decaying of the moral fibre of the society.

The statements made above suggest that modernization has eroded very core of Ubuntu which is humanity and are in line with Ubuntu principle of respect for human dignity and equality that suggests respect of all individuals irrespective of gender, race, age, status and class. The South African constitution affirms this principle. These principles are enshrined in the South African Constitution. Ubuntu enhances family and community values that include fidelity, responsibility, nurturing of children, and support for the elderly, promotes the culture of care and generosity. It is in the African culture to care for our elderly parents. The functioning of the family is made easier when these principles are observed. A child growing in an abusive environment becomes an abusive adult. According to the principles of psychodynamic model childhood experiences determine adulthood behaviour. The society has neglected the Ubuntu that moulds the character and instils morals.

\subsection{Collaboration between western and Ubuntu therapy}

Most participants said that there is no collaboration between the Health centres and the traditional healers even though so much was said post-1994 that traditional healing was legislated. Some participants said there are some areas where collaboration has started even though they are still minimal, citing circumcision. The initiate has to be screened by the medical doctor for any STIs before traditional surgeon cuts off the foreskin. They said in their area this collaboration has worked well and they have never lost any initiate.

One older participant seriously explained the collaboration,

"Intsebenziswano ingakhona nje ngokuba seyikho kulento yokwaluka.Inkwenkwe iqala kugqirha esibhedlele ihlolwe ukuba iphilile naphambi kokuba iye engcibini. Asinawuphika kuba ingxaki zezigulo ezikhoyo, ugqirha uye azibone kwamsinya ngokuhlola igazi."

[Collaboration is possible as it has started already in circumcision. The boy starts at the hospital for examination before proceeding to the traditional surgeon for the procedure. We cannot deny there are so many diseases in our days and the doctors are able pick them sooner because the test blood] (Frowning).

Two participants have responded amusedly by saying,

"Kwindima yokumisela abafazi xa kunzima ukukhulelwa kuba ogqirha basoyiswa bona ukumisela, basuke bangxame ngotyando oluye lungasebenzi sele belwenzile. Kanti kufuneka nje kuyothethwa nje emaxhantini okanye kufuneka nje ibhotile.Xa umfazi sele ekhulelwe bangambelekisa kuba siyavuma uba abantwana mabagonywe"

[In cases of making a woman to be able to conceive, collaboration can work because doctors are unable to. They just operate and most operations do not succeed. Whereas all what is needed is to speak to the ancestors or a bottle of traditional medicine. They can deliver the baby] (amused).

One participant laughingly explained,

"Kwindima yokukhupha amafufunyana, umoya omdaka ufuna siwulwe ngomnye umoya (umoya wezinyanya) nangamayeza ethu esintu. Siqhumise kube yilonto sitshize ngeyeza jikelele apha endlini."

[Collaboration in the area of casting out demon is not possible, evil spirits need to be fought by the spirit (ancestral spirit) and with our traditional medicines. We burn incense and sprinkle with medicine around the house] (Laughing loudly and others joined the laughter). 
The above quotes depict the areas and possible areas of collaboration. According Broodryk (2010) experienced traditional healers are seen as being of the essence to success of primary health care initiatives, such as immunisation programmes, family planning and HIVIAIDS education. According to Ramose (2005), Walaza (2005) and Broodryk (2010) traditional healers claim to treat the symptoms of an illness, the root cause of the illness and the patients environment through a holistic caring approach.

Contrary to the above statements, some participants did not agree that collaboration or integration of western and traditional healing could ever work. They mentioned the issue of secretiveness of traditional healers in how they mix their herbs. A bottle of medicine has to show what the medicine contains.

One participant said,

\begin{abstract}
"Intsebenziswano inganzima kuba amagqirha awazichazi izinto abenza ngazo amayeza abo, bawagcina kubo bowufa nabo okanye bayinike abantwana babo. Nendlela yokucoceka kwezinto ekugalelwa kuwo amayeza" (Frowning). [Collaboration could be very difficult because traditional healers do not reveal the herb they are using to make their medicines; they keep them a secret until they die or pass on to their children. Even the containers they use for mixing and the bottles are not sterilized].
\end{abstract}

A study conducted by Mall (2007) on attitudes of HIV positive patients to African traditional healers and their practices revealed that concurrent use of ARV and traditional healing medicines poses a threat in HIV patients' lives. Healthy workers interviewed argued that some traditional medicines induce diarrheoa and vomiting. Moodley (2007) argues that for a collaboration to take place, negotiations between the healer and the therapist have to occur, where they will both recommend what is best for the patient. According to Ubuntu principles, tolerance and respect of one's culture and belief system is crucial. Collaboration could work between western and Ubuntu therapy if only there is mutual respect, tolerance, transparency, sharing of information and expertise, and unity among therapists. Currently, Ubuntu therapy is still undermined by many western therapists.

\title{
4. Summary and Recommendations
}

This study focuses on the role of Ubuntu in family therapy. According the African culture, the family is driven by a set of rules, has assigned roles for its members, has an organised power structure, has developed forms of communication, and has clearly defined ways of negotiating and problem solving strategies (Golden \& Golden, 2008). Each family is moulded by a number of factors which include, among others, the community and their belief system. Juma (2011) asserts that the kind of therapy the family uses is determined by their belief system. According to Tutu (2004) Ubuntu can also be articulated as a multi-dimensional concept and a traditional African way of life which embraces such values as respect for human beings, human dignity, and also human life, hospitality, caring about others, solidarity, collective sharing, humility, interdependence, caring about others and being eager to go the extra mile for the sake of another (Tutu, 2004).

The research findings reveal that people of Golf Course Community have a broad understanding of Ubuntu and it as the key virtues that can bring about harmony in their families and in society at large. They also view Ubuntu principles as the salvation not only to their family problems but to the broader community as well. It is evident that most of their problems emanate from neglecting their roots, who they are and where they are coming from. Furthermore, the participants also revealed that Ubuntu is lacking among communities as result they are living in fear and as result this led to the erosion of the moral fibre of the society.

The study further reveals that families have forsaken their cultures and traditions where the ancestors and traditional healers play a significant role in solving their family problems. The participants gave an explanation on the role of the elders in their culture and yet they are not respected by their own children.

The limitation of the study was that the researcher struggled to find participants due to the non-availability of the Residents Association chairperson for entry clearance. It was time consuming to locate the participants and this has put the researcher to work under a lot of pressure. Even though this study can be transferable into contexts outside the study environment but it cannot be generalised due to the minute number of the participants that have been utilised in the study.

Ubuntu principles have been commended and applied in various contexts worldwide. Ubuntu plays a vital role in dealing with psychosocial problems and thorough research should be conducted if we are to heal families. The following two pronged recommendations have been made:

- Proposed intervention and further research. 
- Parents should teach their children at an early age about Ubuntu (primary socialization)

- The Department of Education should inculcate Ubuntu within the school curriculum as a subject from primary level to tertiary level so as to generate caring and responsible citizens.

- The Department of Arts and Culture should develop programmes that are aimed at reviving and restoring Ubuntu in our communities and work in collaboration with community elders.

- Institutions like Icamagu Institute should teach younger generation to embrace their cultures.

- Collaboration between western therapists and Ubuntu therapist or traditional healers.

- Government should facilitate discourses for all stakeholders (government departments, communities, western therapist and Ubuntu therapists).

Proposed research

- Future research based on the above mentioned limitation on sampling is that future studies should be conducted with larger and more diverse samples; moreover, data should be gathered on a wider variety of demographics and cultural belief systems and practices.

- There may be a need for collaborative relationships to be developed between Western based therapist and traditional healers in an endeavour to afford clients with the best services.

- The focus of future research therefore, given the results of this study, should be to create specific departments in African institutions/universities to embark on comprehensive field research within psychology departments. These studies can be on various themes on Ubuntu with a view of creating a concrete foundational structure on which African Indigenous Psychology can be built and established as an alternative to Western Psychology.

\section{References}

Barnes, G.G. (2004). Family therapy in changing times: Basic text in Counselling and psychotherapy. London: Palgrave Macmillan Limited.

Braun, V. \& Clarke, V. (2006).Using thematic analysis for psychology, Qualitative Research in Psychology, 3:2, 77-101.

Broodryk, J. (2006). Ubuntu life-coping from Africa. Randburg: Knowres Publishing (Pty) Ltd.

Broodryk, J. (2010). Understanding South Africa: The Ubuntu way of living. Tshwane: Published by Ubuntu School of Philosophy.

Burns, N. \& Grove, S. (2005).The Practice of Nursing Research: Conduct, Critique \& Utilization.4th edition. Philadelphia: Saunders Company Publishers.

Creswell, J.W. (2009). Research design: qualitative, quantitative and mixed methods approaches. London: SAGE.

De Vos, A. S.; Strydom, H. \& C.B. Fouché \& Delport, C.S.L. (2012). Research at Grassroots: For Social Sciences and Human Service Professions. th $^{\text {th }}$ ed. Cape Town: Van Schaik Publishers.

Engelbrecht, C. \& Kasiram, M. (2012).The role of Ubuntu in families living with mental illness in the community. South African Family Practice 54(5):441-446.

Hailey, J. (2008). Ubuntu: A Literature Review: A Paper prepared for the Tutu Foundation.

Holborn, L. \& Eddy, G. (2011). A research paper by the South African Institute of Race relations. Johannesburg: South African Family.

Jolley, D.R. (2011). A person is a person through others. Utah: Southern Utah University.

Jönsson, L. \& Stensson, T. (2010). Professional responsibility within substance abuse treatment: In the perspective of the Ubuntu philosophy. Individual portal organisation.

Juma, J. O. (2011). African Worldviews - Their impact on psychopathology and psychological counselling. Pretoria: University of South Africa.

Kasiram, M. \& Oliphant, E. (2007). Indigenizing Family Therapy for South African Use, Journal of Family Psychotherapy Vol. 18 No. 2 pp. 71-82.

Lee, M., Greene, G., Hsu, K.S., Solovey, A., Grove, D., Fraser, J.S., Washburn, P. \& Teater, B. (2009).Utilising Family Strength and resilience: integrative family and systems treatment with children and adolescents with severe emotional and behavioural problems. Family Process, 48: 395 - 416.

Leedy, P.D. \& Ormrod, J.E. (2005). Practical Research: Planning and Design, $8^{\text {th }}$ Edition. New Jersey: Pearson Merrill Prentice Hall.

Louw, D.J. (2008). Ubuntu: an African assessment the religious others. Paper to 20th World Congress of Philosophy, Boston.

Makhele, M.F. (2009). The Experiences of the Batswana Families Regarding Hospice Care of Aids Patients. The North West University.

Mangena, F. (2009). The Search for an African Feminist Ethics: A Zimbabwean Perspective. Journal of International Women's Studies, 11(2): $18-30$.

Masina, N. (2000). Xhosa Practice of Ubuntu for South Africa. Colorado: Lynne Publishers Inc.

Mbigi, L. \& Maree, J. (1995). Ubuntu: The Spirit of African Transformation Management. Randburg: Knowledge Resources,

Mndende, N. (2007). Ubuntu : An assessment of the religious other. Cape Town: Ubuntu Institute.

Moodley, R. (2007). Integrating traditional healing into counselling and psychotherapy. Thousand Oaks, Calif.: Sage Publications.

Nussbaum, B. (2003). Ubuntu: Reflections of a South African on our common humanity. Reflections. Massachusetts Institute of 
Technology, Vol.4.4

Olinger, H.N., Britz, J.J. \& Olivier, M.S. (2007). Western privacy and or Ubuntu? Some critical comments on the influences in the forthcoming data privacy bill in South Africa. International Information and Library Review, 39(1), 31-43

Ponterotto, J. (2005). Journal of Counselling Psychology: A Primer on Research Paradigm and Philosophy of Science. Fordman University.

Ramose, M.B., (2005). African Philosophy through Ubuntu. Harare: Mond Book Publisher.

Statistical Services South Africa, Quarterly Labour Force Survey, 2013.

Stommel, M. \& Willis, C.E. (2004). Clinical research. Concepts and principles for advanced practice. USA: Lippincott, Williams \& Wilkins.

Terre Blanche, M., Durrheim, K. \& Painter, D. (2006). Research in Practice: applied methods for social sciences. Cape Town: University of Cape Town Press.

Tlou, E. (2014). Re-understanding family therapy in the African context. Paper presented at the $1^{\text {st }}$ International Congress of the Forum of African Psychology.

Washington, K. (2010). Zulu Traditional Healing, Afrikan Worldview and the Practice of Ubuntu: Deep Thought for Afrikan/Black Psychology. San Francisco State University. 